\title{
Pneumococcal vaccination responses in adults with subnormal lgG subclass concentrations
}

\author{
Antony R. Parker ${ }^{1}$, Markus Skold ${ }^{1}$, Stephen Harding ${ }^{1 *}$, J. Clayborn Barton², Luigi F. Bertoli ${ }^{3}$ and James C. Barton 23,4
}

\begin{abstract}
Background: We sought to compare Pneumovax ${ }^{\oplus} 23$ responses in adults with subnormal IgG subclass concentrations. We studied adults with normal total lgG, frequent/severe respiratory infection, and subnormal $\lg G 1$, $\lg \mathrm{G} 3$, or $\lg \mathrm{G} 1+\lg \mathrm{g} 3$ before and after Pneumovax ${ }^{\oplus} 23$. We defined response as serotype-specific $\lg \mathrm{G}>1.3 \mu \mathrm{g} / \mathrm{mL}$ and aggregate response as $\lg \mathrm{G}>1.3 \mu \mathrm{g} / \mathrm{mL}$ for $\geq 70 \%$ of all serotypes tested. We compared patients with and without serotype-specific responses and performed logistic regression on aggregate responses using: age; male sex; body mass index; autoimmune condition(s); atopy; other allergies; subnormal IgGSc immunophenotypes; IgA; and lgM.

Results: There were 59 patients (mean age $44 \pm 13$ (SD) years; $83.1 \%$ women). Median days between pre- and postPneumovax ${ }^{\otimes} 23$ testing was 33 (range 19-158). The median post-vaccination summated concentration of serotypespecific lgG was higher in patients with subnormal lgG1 than subnormal $\lg G 3$ (responders and non-responders). All subnormal $\lg G 1+\lg G 3$ non-responders responded to serotypes 8, 9 and 26, unlike other non-responders.

Subnormal IgG3 responders had lower responses to serotypes 1, 4, 12, 23, 26, and 51. Subnormal IgG3 nonresponders had higher responses to serotypes $1,3,8,9,12,14,19,51$, and 56 . Response rates decreased with increasing age. Aggregate responders were: subnormal lgG1, 54\%; lgG3, 46\%; and lgG1 + lgG3, 46\%. Regression on aggregate response revealed lower response with male sex (odds ratio $0.09[95 \% \mathrm{Cl} 0.01,0.77]$ ) and atopy $(0.17$ $[0.03,0.83])$.
\end{abstract}

Conclusions: Serotype-specific lgG responses to Pneumovax ${ }^{\oplus} 23$ were greater in patients with subnormal $\lg G 1$ than subnormal IgG3. Male sex and atopy were associated with lower aggregate responses.

Keywords: IgG subclasses, Vaccine response, Pneumococcal, Pneumovax ${ }^{\circledR} 23$, Primary immunodeficiency

\section{Background}

Subnormal IgG subclass (IgGSc) concentrations in some adults represent a primary immunodeficiency disorder(s) characterized by frequent or severe respiratory tract infections, suboptimal IgG responses to pneumococcal polysaccharides, and increased prevalence of autoimmune disorders and atopy [1-3]. The subnormal serum concentrations are mainly present in any one or more of three main subclasses IgG1, $\operatorname{IgG2}$, or IgG3 [4, 5]. Molecules of the four respective IgG subclasses are characterized by distinct induction

\footnotetext{
* Correspondence: stephen.harding@bindingsite.com

'The Binding Site Group Limited, 8 Calthorpe Road, Birmingham B15 1QT, UK Full list of author information is available at the end of the article
}

antigens or allergens, antigen binding, immune complex formation, complement activation, half-life, and other properties. Accordingly, patients with different subnormal IgGSc immunophenotypes have dissimilar predisposition to infection [6].

IgG1 production is induced by exposure to soluble and membrane protein antigens and allergens. Some individuals with subnormal IgG1 have frequent or severe infections, especially of the respiratory tract [7, 8]. Antibody responses to bacterial capsular polysaccharide antigens are associated with low serum $\operatorname{IgG2}[6,9,10]$. Some persons with subnormal IgG2 have increased risk of respiratory tract infections due to encapsulated bacteria, although others are apparently healthy $[11,12]$. Some persons with subnormal

(c) The Author(s). 2019 Open Access This article is distributed under the terms of the Creative Commons Attribution 4.0 International License (http://creativecommons.org/licenses/by/4.0/), which permits unrestricted use, distribution, and 
IgG3 also have subnormal concentrations of other subclasses, especially IgG1 [13, 14]. Some allergens and parasites elicit IgG4 responses [15, 16], but the clinical significance of subnormal IgG4, if any, is unclear.

Some patients with subnormal IgGSc respond to certain vaccines and others do not $[8,17-19]$. In a study of $17 \mathrm{pa-}$ tients with subnormal IgGSc, 14 patients who responded to 23-valent pneumococcal polysaccharide vaccination (PPSV23) had no further progression of respiratory tract infections, whereas three PPSV23 non-responders required antibiotic treatment [20]. van Kessel and colleagues reported that following vaccination with PPSV23, non-responders with subnormal IgG1 to the measured 14 pneumococcal polysaccharide serotypes (PPS), had increased risk of infection with Streptococcus pneumoniae, and a greater proportion had received treatment with corticosteroids [21]. Because IgGSc levels and vaccination response are independent but overlapping markers of Blymphocyte and plasma cell function, it is plausible that the combination of a lack of vaccination response and subnormal IgGSc increases risk of corresponding infection(s).

In this report, we describe a retrospective analysis of characteristics of 59 adults with subnormal IgGSc concentrations but normal IgG. We report whether they did or did not respond to PPSV23 and their concentrations of pre- and post-PPSV23 serotype-specific IgG. We discuss the relationships between subnormal IgGSc immunophenotypes and other attributes of the present patients with specific and aggregate IgG responses to PPSV23 and the pertinence of the present results to infection susceptibility and prevention in patients with subnormal IgGSc.

\section{Methods}

\section{Subject selection}

Performance of this work was reviewed by the Institutional Review Board of Brookwood Medical Center, Alabama. Obtaining informed consent was not required because this study involved evaluation of observations obtained in routine medical care. We studied the records of unrelated non-Hispanic white adults ( $\geq 18$ years of age) referred to a single practice in a large suburban medical center that evaluates and treats many adult patients with primary immunodeficiency. All patients presented with frequent or severe bacterial infections of the upper or lower respiratory tract and were diagnosed to have IgG subclass deficiency [22]. By selection, all of the present patients had normal total serum IgG. Autoimmune conditions, atopy, and other allergy manifestations were defined as previously described [23]. The present patients were evaluated during the interval 2012-2018.

\section{Other conditions}

Body mass index was computed as $\mathrm{kg} / \mathrm{m}^{2}$. We classified diabetes according to the criteria of the American Diabetes Association [24].

\section{Polyvalent pneumococcal polysaccharide vaccination}

S. pneumoniae serotype-specific IgG concentrations were measured before and after PPSV23 (Pneumovax ${ }^{\circ} 23$; Merck \& Co., Inc., Kenilworth NJ, USA). The median interval between pre- and post-PPSV23 testing was 33 days (range 19-158 days).

On 30 December 2011, PCV13 (Prevnar13 ${ }^{\circ}$, Wyeth Pharmaceuticals, Inc., Philadelphia, PA, USA) was approved for use in the US among adults aged $\geq 50$ years to prevent pneumonia and invasive disease caused by $S$. pneumoniae serotypes contained in the vaccine [25]. On 13 August 2014, the routine use of PCV13 among adults aged $\geq 65$ years was recommended in series with PPSV23, the vaccine then recommended for adults aged $\geq 65$ years [25]. In late 2018, the US Centers for Disease Control and Prevention recommended pneumococcal vaccination (both PPSV23 and PCV13) for adults ages 19-64 years who have certain medical conditions or who smoke, including those with congenital or acquired immunodeficiency. The US Centers for Disease Control and Prevention now recommends pneumococcal vaccination for all adults 65 years or older (both PPSV23 and PCV13) [26]. Although none of the present adults reported that they had received PCV13, the possibility that some of them received PCV13 as children cannot be excluded.

\section{Laboratory methods}

All testing was performed before IgG replacement therapy was initiated. Serum Ig concentrations were measured using standard methods at a single reference laboratory (Laboratory Corporation of America, Burlington $\mathrm{NC}$, USA). We defined mean $\pm 2 \mathrm{SD}$ as reference ranges for all Ig concentrations. Ig reference ranges employed were: IgG $7.0-16.0 \mathrm{~g} / \mathrm{L} \quad(700-1600 \mathrm{mg} / \mathrm{dL})$; IgG1 $4.2-12.9 \mathrm{~g} / \mathrm{L}(422-1292 \mathrm{mg} / \mathrm{dL}) ; \operatorname{IgG} 21.2-7.5 \mathrm{~g} / \mathrm{L}$ (117-747 mg/dL); $\quad$ IgG3 $0.4-1.3 \mathrm{~g} / \mathrm{L} \quad(41-129 \mathrm{mg} / \mathrm{dL}) ;$ IgG4 $\quad 0-2.9 \mathrm{~g} / \mathrm{L} \quad(1-291 \mathrm{mg} / \mathrm{dL}) ; \quad \operatorname{IgA} \quad 700-4000 \mathrm{mg} / \mathrm{L}$ (70-400 mg/dL); and IgM 400-2300 mg/L (40-230 mg/ dL). Subnormal Ig concentrations were defined as those below the corresponding reference limits.

Pre- and post-PPSV23 serotype-specific IgG antibodies were measured by clinical laboratories (Laboratory Corporation of America, Burlington NC, USA and ViraCor-IBT, Lee's Summit MO, USA) and included $S$. pneumoniae serotypes $1,3,4,8,9.12,14,19,23,26,51$, 56,57 , and 68. Diluents for patient samples contained Cpolysaccharide and polysaccharide type 22 . The sums of 
post-PPSV23 serotype-specific IgG concentration in test panels were defined as summated concentrations.

\section{Response to PPSV23}

We defined protective serotype-specific IgG levels as > $1.3 \mu \mathrm{g} / \mathrm{mL}$. We defined responders as patients who achieved protective levels of serotype-specific IgG postPPSV23. We defined aggregate PPSV23 response as serotype-specific IgG $>1.3 \mu \mathrm{g} / \mathrm{mL}$ for $\geq 70 \%$ of serotypes tested post-PPSV23.

\section{Statistics}

The analytic data set consisted of complete observations on 59 patients with subnormal IgGSc and total serum IgG $>700 \mathrm{mg} / \mathrm{dL}$. For some analyses, we separated patient data into three groups: 1) subnormal IgG1;2) subnormal IgG3; and 3) subnormal IgG1 + IgG3. Descriptive data are displayed as enumerations, percentages, mean \pm $1 \mathrm{SD}$, or mean $95 \%$ confidence intervals $(\mathrm{CI})$. Age and BMI data were normally distributed and were compared using Student's t-test (two-tailed). Proportions were compared using Pearson's $X^{2}$ test or Fisher's exact test, as appropriate. We computed odds ratios (OR) 95\% CI for some observations. Means of continuous variables among three patient subgroups were compared using one-way analysis of variance (ANOVA) or Kruskal-Wallis one-way ANOVA, as appropriate. Median concentrations were compared using Mann-Whitney U Test and Spearman's rank test to assess the association between pneumococcal summation and coverage. Dichotomous variables in frequency analyses were: male; diabetes; autoimmune condition(s); atopy (allergic asthma, allergic rhinitis, or allergic dermatitis/eczema); and other allergy (urticaria, angioedema, or anaphylaxis). Total clinical variables were calculated from these dichotomous variables.

We compared the general characteristics of patients who did or did not respond to pneumococcal polysaccharides using univariate analyses. We also performed logistic multivariable regressions on aggregate IgG response to pneumococcal polysaccharides to identify significant associations using these independent variables: age at diagnosis; male sex; body mass index (BMI); autoimmune condition(s); atopy; other allergies; subnormal IgG1; subnormal IgG3; subnormal IgG1 + IgG3; and serum levels of IgA and IgM. We computed OR of independent variables with significant associations. Dichotomous variables in frequency analyses were: male; diabetes; autoimmune condition(s); atopy (allergic asthma, allergic rhinitis, or allergic dermatitis/eczema); and other allergy (urticaria, angioedema, or anaphylaxis). Total clinical variables were calculated from these dichotomous variables. Analyses were performed with GraphPad Prism v. 5.04 (GraphPad Software, Inc., La
Jolla, CA, USA), Excel 2000 (Microsoft Corp., Redmond, WA, USA), and GB-Stat ${ }^{\circ}$ (v. 10.0, 2003, Dynamic Microsystems, Inc., Silver Spring, MD, USA). We defined values of $p<0.05$ to be significant. Bonferroni corrections were applied to control the type I error rate at 0.05 for multiple univariate comparisons.

\section{Results}

General characteristics of patients with subnormal lgGSc The proportions of deficiencies in 59 patients with subnormal IgGSc were: subnormal IgG1 22.0\% $(n=13)$; subnormal IgG3 55.9\% $(n=33)$; and subnormal IgG1 + IgG3 $22.0 \%(n=13)$ (Table 1$)$.

Two patients (3.7\%) had subnormal IgA. Three patients (5.1\%) had subnormal IgM. $\chi^{2}$ analysis of the proportions of men in the three subnormal IgGSc groups rejected the null hypothesis $(p=0.03)$. This was due to the lower proportion of men with subnormal IgG3 than subnormal IgG1 + IgG3 (6.1\% vs. $38.5 \%$, respectively; $p=$ 0.014) (Table 1). Proportions of patients with diabetes, autoimmune condition(s), atopy, and other allergy did not differ significantly among the three groups. One-way ANOVA revealed no significant differences of age, BMI, serum IgA, serum IgM or days between pre- and postPPSV23 testing among the three groups (Table 1).

In two of the three subnormal IgGSc groups, there was a significant positive Spearman rank correlation of total levels of pneumococcal serotype-specific IgG and percentage serotype coverage per patient (subnormal IgG1, rho = $0.66, p=0.02$; subnormal IgG3, rho $=0.8, p<0.0001$; and subnormal IgG1 $+\operatorname{IgG} 3$, rho $=0.52, p=0.07$ ).

\section{Serotype-specific lgG}

Serum concentrations of anti-pneumococcal serotype specific IgG in the different subnormal IgGSc groups are displayed in Figs. 1 and 2. In PPSV23 responders, the trend in anti-pneumococcal IgG was subnormal IgG1 > subnormal IgG3 > subnormal IgG1 + IgG3. For serotypes 3,19 and 68 , the median concentration of anti-pneumococcal IgG was greater in patients with subnormal IgG3 than in patients with subnormal IgG1 and for serotypes 9 and 68 was higher in patients with subnormal IgG1 + IgG3 than patients with subnormal IgG3. In PPSV23 non-responders, the trend of serum levels of antipneumococcal antibodies was subnormal IgG1 $>$ subnormal IgG1 + IgG3 > subnormal IgG3. For serotypes 26 and 57, the concentrations of anti-pneumococcal IgG were higher in patients with subnormal IgG3 than in patients with subnormal IgG1.

We investigated the percentage response and non- response to each serotype tested in responders and nonresponders across the three subnormal IgGSc immunophenotype groups (Table 2). 
Table 1 Characteristics of 59 index patients with subnormal lgGSc and normal total $\lg G^{a}$

\begin{tabular}{|c|c|c|c|c|}
\hline Characteristic & Subnormal lgG1 & Subnormal lgG3 & Subnormal lgG1+ lgG3 & All patients \\
\hline$n$ & 13 & 33 & 13 & 59 \\
\hline Mean age, years \pm SD & $34 \pm 13$ & $45 \pm 12$ & $48 \pm 13$ & $44 \pm 13$ \\
\hline Men, \% (n) & $23.1(3)$ & $6.1(2)$ & $38.5(5)$ & $16.9(10)$ \\
\hline Diabetes, \% (n) & 0 & $6.1(2)$ & $15.1(2)$ & $6.8(4)$ \\
\hline Mean $\mathrm{BMl}, \mathrm{kg} / \mathrm{m}^{2} \pm \mathrm{SD}$ & $27.3 \pm 7.8$ & $26.6 \pm 5.7$ & $30.8 \pm 12.8$ & $28.1 \pm 8.2$ \\
\hline Autoimmune condition(s), \% (n) & $23.1(3)$ & $42.4(14)$ & $30.8(5)$ & $37.3(22)$ \\
\hline Atopy ${ }^{b}, \%(n)$ & $23.1(3)$ & $36.4(12)$ & $15.4(2)$ & $28.8(17)$ \\
\hline Other allergy ${ }^{c}, \%$ (n) & $53.8(7)$ & $51.5(17)$ & $46.2(6)$ & $50.8(30)$ \\
\hline Mean $\lg A, \mathrm{mg} / \mathrm{dL} \pm \mathrm{SD}$ & $154 \pm 74$ & $206 \pm 106$ & $196 \pm 91$ & $200 \pm 95$ \\
\hline Mean lgM, mg/dL $\pm S D$ & $263 \pm 86$ & $120 \pm 99$ & $104 \pm 75$ & $117 \pm 90$ \\
\hline Median days between pre-, post-PPSV23 tests (range) & $32(27-47)$ & $35(19-129)$ & $32(19-158)$ & $33(19-158)$ \\
\hline
\end{tabular}

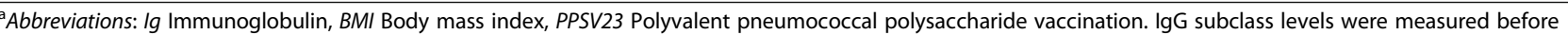
IgG replacement therapy. Mean \pm 2 SD was defined as reference ranges for all lg measurements. lg reference ranges are: total lgG $7.0-16.0 \mathrm{~g} / \mathrm{L}$ ( $700-1600 \mathrm{mg} / \mathrm{dL}$ ); lgG1 4.2-12.9 g/L (422-1292 mg/dL); lgG2 1.2-7.5 g/L (117-747 mg/dL); lgG3 0.4-1.3 g/L (41-129 mg/dL); lgG4 0-2.9 g/L (1-291 mg/dL); lgA 700-4000 mg/L (70$400 \mathrm{mg} / \mathrm{dL}) ; \mathrm{lgM} 400-2300 \mathrm{mg} / \mathrm{L}(40-230 \mathrm{mg} / \mathrm{dL})$. Subnormal $\mathrm{lg}$ concentrations were defined as those below the corresponding reference limits

${ }^{\mathrm{b}}$ Allergic asthma, allergic rhinitis, or allergic dermatitis/eczema

'Urticaria, angioedema, or anaphylaxis

One responder in each immunophenotype group had $100 \%$ response to serotypes 3, 8, 9, 14, 26 and 68. Non-responders with subnormal IgG1 + IgG3 had 100\% response to serotypes 8, 9 and 26, unlike non-responders with subnormal IgG1 or subnormal IgG3. Among patients with subnormal IgG3, non-responders had less response to serotypes $1,3,8,9,12,14,19,51,56$ and the responders had less response to serotypes 1, 4, 12, 23, 26 and 51 (Table 2).

\section{Summated serotype-specific IgG}

The summated concentrations of serotype-specific IgG antibodies differed across the subnormal IgGSc groups (Fig. 3). In responders, we observed: subnormal IgG1, median $115 \mu \mathrm{g} / \mathrm{mL}$ (range 50-297); subnormal IgG3, median $54 \mu \mathrm{g} / \mathrm{mL}$ (range 32-351); and subnormal IgG1 + IgG3, median $55 \mu \mathrm{g} / \mathrm{mL}$ (range 33-204). In non-responders, we observed: subnormal IgG1, median $35 \mu \mathrm{g} / \mathrm{mL}$ (range 2381); subnormal IgG3, median $19 \mu \mathrm{g} / \mathrm{mL}$ (range 8-85); and subnormal IgG1 + IgG3, median $34 \mu \mathrm{g} / \mathrm{mL}$ (range 4-47). For all comparisons, $p=0.04$ (Fig. 3). The median summated concentration of serotype-specific IgG antibodies was significantly higher in subnormal IgG1 non-responders than subnormal IgG3 non-responders $(p=0.01)$.

The summated concentrations of serotype-specific IgG decreased with increasing age, and were significant in nonresponders with subnormal IgG1 (rho $=-0.79, p=0.048$ ) and subnormal IgG3 (rho $=-0.71, p=0.007$ ) (Fig. 4), but were not significantly associated with BMI or serum levels of IgG1, IgG3, IgG4, IgA, or IgM (data not shown).

\section{Clinical variables and PPSV23 response}

The prevalence of clinical variables (total number of variables and atopy) was higher in PPSV23 non-responders than responders for all three subnormal IgGSc immunophenotype groups and in patients with subnormal IgG3 than in patients with subnormal IgG1 and subnormal IgG1 + IgG3. The prevalence of total clinical variables and atopy per person was higher in patients with subnormal IgG3 and PPSV23 non-responsiveness than those who did respond ( 1.3 vs. $0.4, p=0.009$ and 1.6 vs. $0.1, p=0.003$, respectively) (Table 3 ).

Within groups of PPSV23 non-responders, the frequency of total clinical variables per person was higher in patients with subnormal IgG3 than in patients with subnormal IgG1 (1.3 vs. 0.4 , respectively; $p=0.04$ ). The median weight of PPSV23 non-responders with subnormal IgG1 was greater than that of PPSV23 non-responders with subnormal IgG3 (171 pounds (range 148-322) vs. 136 pounds (range 104-255), respectively; $p=0.03$ ).

\section{Clinical variables and serotype-specific IgG responses}

There was a significant difference between the prevalence of atopy and total clinical variables in non-responders compared with the corresponding data of responders with subnormal IgG3, but there were no significant differences between responders and nonresponders in either the subnormal IgG1 or subnormal IgG1 + IgG3 groups (data not shown). In patients with subnormal IgG3 who were non-responders, atopy was associated with higher concentrations of IgG specific for antigens 3,4,14, 56 and 68, and the total number of clinical variables was associated with higher concentrations of IgG specific for serotypes 1, 3 , and 14 (Table 3). There was a strong positive association between low concentration of $1,3,14$, and 51 serotype-specific IgG in subnormal IgG3 PPSV23 

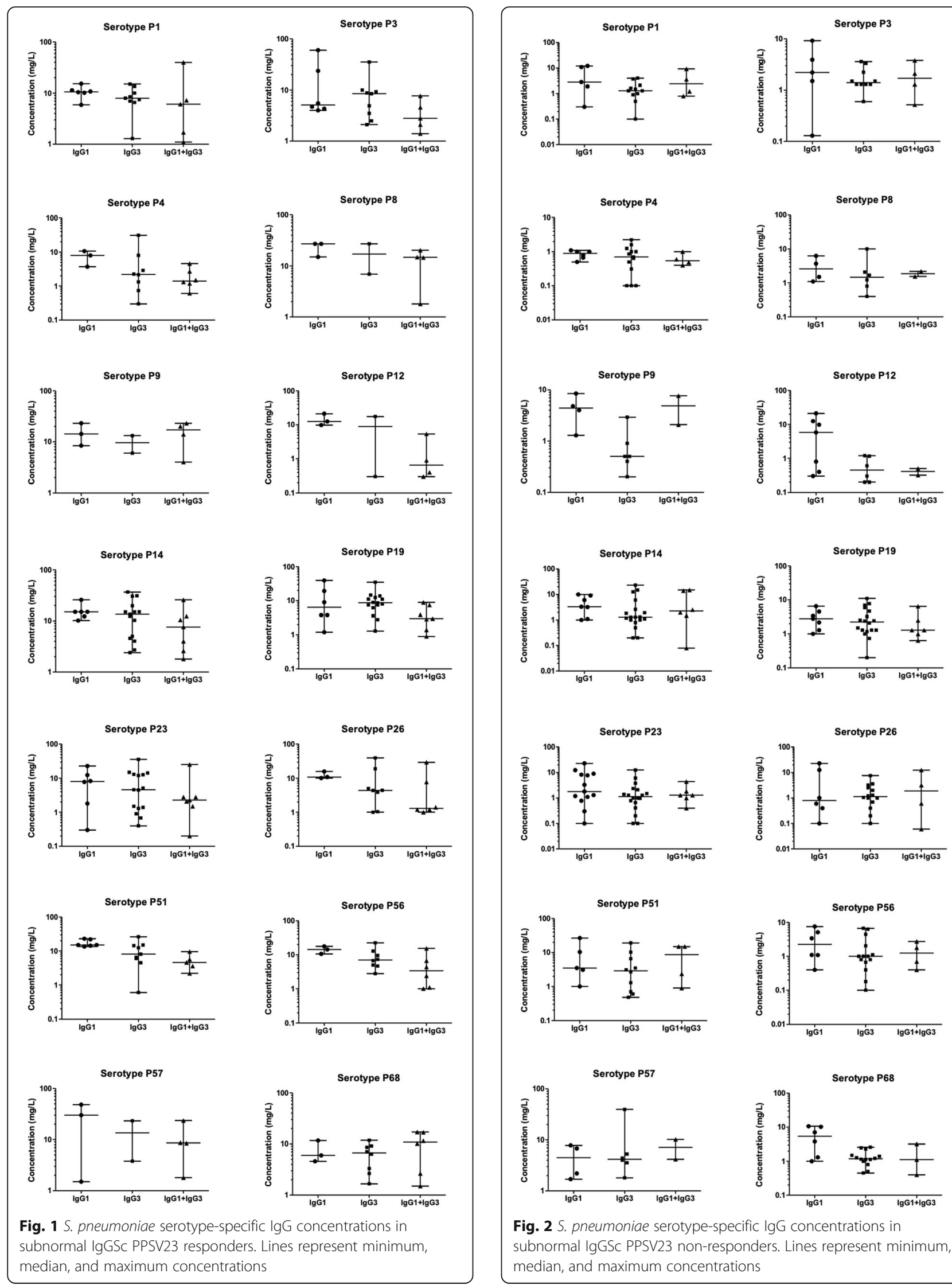

Fig. 2 S. pneumoniae serotype-specific lgG concentrations in

subnormal IgGSC PPSV23 non-responders. Lines represent minimum, median, and maximum concentrations 
Table 2 Non-responders to pneumococcal serotypes in 59 index patients with subnormal lgGSc and normal total lgG

\begin{tabular}{|c|c|c|c|c|c|c|c|c|c|c|c|c|c|c|}
\hline S. pneumoniae serotype & 1 & 3 & 4 & 8 & 9 & 12 & 14 & 19 & 23 & 26 & 51 & 56 & 57 & 58 \\
\hline Subnormal lgG1, \% NR & 20 & 20 & 100 & 25 & 25 & 75 & 29 & 29 & 71 & 66 & 20 & 50 & 0 & 17 \\
\hline Subnormal lgG1, \% R & 0 & 0 & 0 & 0 & 0 & 0 & 0 & 17 & 17 & 0 & 0 & 0 & 0 & 0 \\
\hline Subnormal lgG3, \% NR & 55 & 50 & 85 & 50 & 85 & 100 & 56 & 40 & 72 & 64 & 40 & 71 & 0 & 64 \\
\hline Subnormal lgG3, \% R & 11 & 0 & 25 & 0 & 0 & 50 & 0 & 7 & 27 & 25 & 13 & 0 & 0 & 0 \\
\hline Subnormal lgG1 + lgG3, \% NR & 50 & 50 & 100 & 0 & 0 & 100 & 17 & 66 & 66 & 0 & 25 & 50 & 0 & 66 \\
\hline Subnormal lgG1 + lgG3, \% R & 20 & 0 & 33 & 0 & 0 & 75 & 0 & 14 & 14 & 0 & 0 & 33 & 0 & 0 \\
\hline
\end{tabular}

${ }^{a}$ Abbreviations: IgGSC IgG subclass(es), NR Non-responders, $R$ Responders. We defined responders as patients who achieved protective levels of serotype-specific IgG post- polyvalent pneumococcal polysaccharide vaccination

responders and an association with male gender (Table 4). In PPSV23 non-responders, lower concentrations of some serotype-specific IgG were associated with a higher prevalence of: atopy (serotypes 4, 14, 56 and 68); autoimmune condition(s) (serotypes 3 and 51); other allergies (serotypes 3 and 51) and total clinical variables (serotype 14) (Table 4).

\section{Aggregate IgG responses}

The percentages of aggregate responders were: subnormal IgG1, 54\%; subnormal IgG3, 46\%; and subnormal IgG1 + IgG3, 46\%. In univariate analyses, the prevalence of atopy was significantly lower in patients who were aggregate IgG responders than in patients who were aggregate non-responders (Table 5). In a logistic multivariable regression on aggregate IgG responses, there were two significant associations: male sex $(p=0.03$; OR 0.09 [95\% CI $0.01,0.77])$; and atopy ( $p=0.03$; OR 0.17 [95\% CI $0.03,0.83])$. Significance of the model was 0.083 . This model accounted for $22.0 \%$ of the deviance of aggregate IgG responses.

\section{Discussion}

The restriction of anti-pneumococcal polysaccharide IgG response post-PPSV23 was greater in our patients with subnormal IgG3 than in patients with subnormal IgG1. Previous studies have reported associations between subnormal IgG3 and respiratory tract infection [19, 27]. Risk for infections due to particular S. pneumoniae serotypes is probably increased in some patients with subnormal IgGSc due to their inability to synthesize specific protective antibodies. For example, impaired production of IgG anti-pneumococcal serotype 3 has been associated with recurrent pneumonia, empyema, septic shock, and increased fatality [28-30]. There is a positive association between invasive pneumococcal infection and impaired production of anti-serotype 4, 14, 51 and 56 [29]. IgG3 is also a key determinant in response to Moraxella catarrhalis and S. pyogenes infections [31, 32].

IgG3 antibodies in commercial intravenous IgG preparations have been reported to have the most potent binding and opsonic activity for S. pneumoniae serotype 6B [33], a major etiology of infections in persons with primary immune deficiency [34]. Individuals with subnormal serum IgA or heavy chain constant region deletions of the $\gamma 2$ gene produce IgG1 and IgG3 antipneumococcal polysaccharide antibodies [35, 36]. Some patients with recurrent bacterial respiratory tract infections and subnormal IgG3 have subnormal subsets of blood T- or B-lymphocytes or impaired lymphocyte function [18, 23, 37, 38]. Patients with recurrent bacterial respiratory tract infections and subnormal IgG3 had less frequent or severe infections after they were treated with IgG devoid of IgG3 [39], suggesting that qualitative

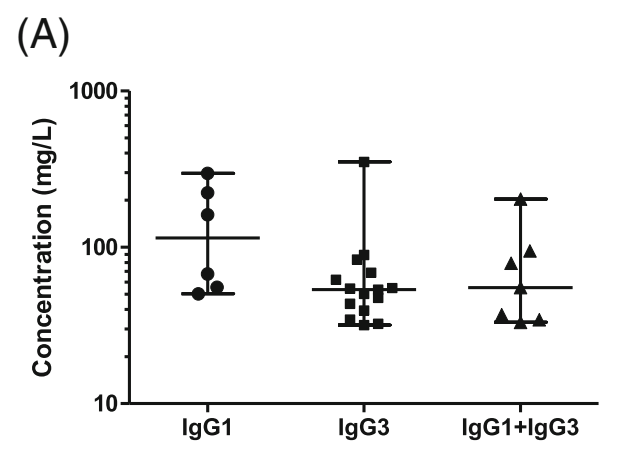

(B)

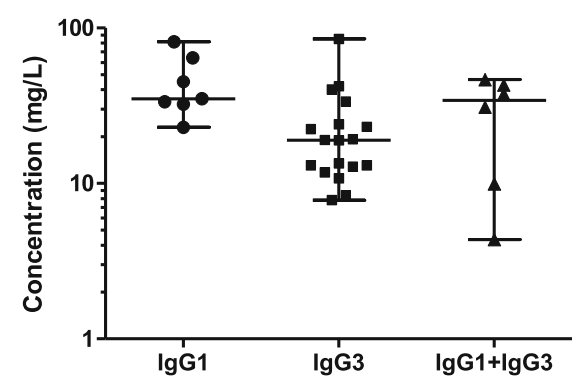

Fig. 3 Summation of S. pneumoniae serotype-specific IgG antibodies. We measured the concentration of all serotype-specific antibodies per patient in subnormal IgGSc groups in a PPSV23 responders (IgG1, $n=6$; IgG3, $n=15$; and $\operatorname{lgG} 1+\operatorname{lgG} 3, n=7)$ and $\mathbf{b}$ PPSV23 non-responders (lgG1, $n=7 ; \lg G 3, n=18 ;$ and $\lg G 1+\lg G 3, n=6)$ 


\section{(A)}

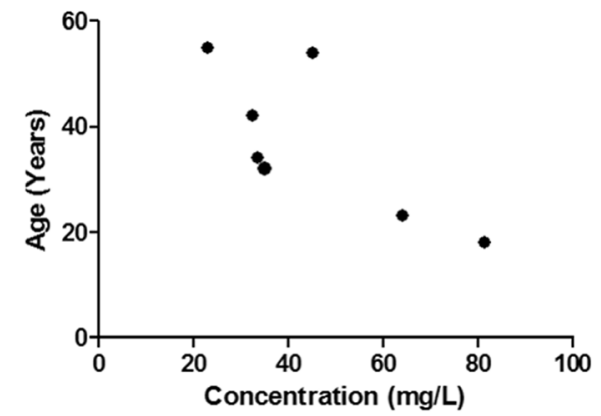

(B)

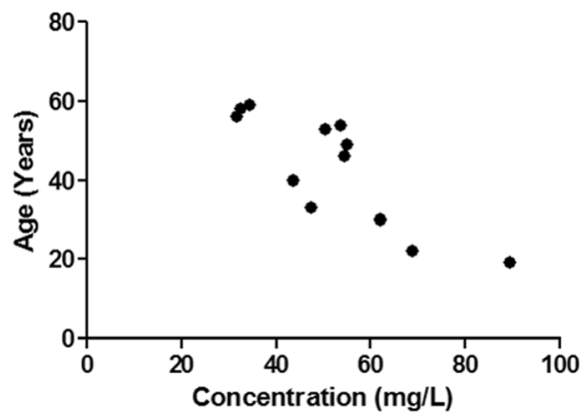

Fig. 4 Influence of age on S. pneumoniae serotype-specific lgG antibodies. Summation of total S. pneumoniae serotype antibodies was positively associated with age in a subnormal lgG1 non-responders and $\mathbf{b}$ subnormal lgG3 responders

deficits in IgG1, IgG2, or possibly IgG4 subclasses increase infection susceptibility. Taken together, these observations indicate that multiple factors in individuals with subnormal IgG3, including suboptimal response to some S. pneumoniae serotype-specific antigens, contribute to increased susceptibility to respiratory tract infection.

In this study, patients with subnormal IgG3 and subnormal IgG1 + IgG3, PPSV23 responders had similar serum concentrations of anti-pneumococcal polysaccharide antibodies. In PPSV23 non-responders, the concentrations were higher in patients with subnormal IgG1 + IgG3. The greater responses to serotypes 8 and 9 and greater serum levels of IgG2 in patients with subnormal IgG1 + IgG3 could partly account for this difference.

In the cohort of 59 patients with subnormal IgGSc, there was a predominance of women, consistent with other subnormal IgGSc case series. A predominance of women was also observed in each of the three subnormal IgGSc immunophenotype subgroups we studied. In univariate analyses, we observed a strong positive association between low concentration of $1,3,14$ and 51 serotype-specific antibodies and male gender. In a logistic regression on aggregate IgG responses, the odds of responses in men were low (0.09 [95\% CI: 0.01, 0.77]). In an analysis of data extracted from 84 studies, Falagas and colleagues concluded that males in all age groups develop respiratory tract infections more frequently than females, except in cases of sinusitis, otitis externa, and probably tonsillitis [40].

There was an inverse correlation of PPSV23 response with age in the present study. This was most evident in non-responders with subnormal IgG1 $(r=-0.79)$ and responders with subnormal IgG3 $(r=0.71)$. In another study, IgG, IgA, and IgM concentrations were lower in elderly adults (aged 70-79 years) than in younger adults (college students) [41]. In another report, IgG responses to PPSV23 were stable in Prevnar13 ${ }^{\circ}$-naive healthy adults as long as 6 years post-PPSV23 [42]. In the current study, the serum levels of post-PPSV23 $S$.

Table 3 Pneumococcal serotype-specific lgG responses and clinical variables in 59 adults with selective subnormal lgG3 ${ }^{a}$

\begin{tabular}{|c|c|c|c|c|}
\hline \multirow{2}{*}{$\begin{array}{l}\text { S. } \\
\text { pneumoniae } \\
\text { Serotype }\end{array}$} & \multirow[t]{2}{*}{ Variable } & \multicolumn{2}{|c|}{ Frequency of dichotomous variables } & \multirow{2}{*}{$\begin{array}{l}P \\
\text { value }\end{array}$} \\
\hline & & Responders $^{\mathrm{b}}$ & Non-responders & \\
\hline 3 & Atopy & 0.4 & 1.3 & 0.009 \\
\hline 4 & Atopy & 0 & 1.6 & 0.007 \\
\hline 14 & Atopy & 0.1 & 1.3 & 0.005 \\
\hline 56 & Atopy & 0 & 1.6 & 0.007 \\
\hline 68 & Atopy & 0 & 1.6 & 0.007 \\
\hline 1 & Total variables & 0.2 & 1.1 & 0.012 \\
\hline 3 & Total variables & 0.1 & 1.6 & 0.003 \\
\hline 14 & Total variables & 0.2 & 1.3 & 0.01 \\
\hline
\end{tabular}

${ }^{a}$ Variables were defined as: male; diabetes; autoimmune condition(s); atopy (allergic asthma, allergic rhinitis, or allergic dermatitis/eczema); and other allergy (urticaria, angioedema, or anaphylaxis). Frequency was calculated as the mean number of each variable or total variables per patient in polyvalent pneumococcal polysaccharide vaccination responders and non-responders

${ }^{b}$ We defined responders as patients who achieved protective levels of serotype-specific IgG post- polyvalent pneumococcal polysaccharide vaccination. We defined protective serotype-specific lgG levels as $>1.3 \mu \mathrm{g} / \mathrm{mL}$ 
Table 4 Frequencies of variables that differed significantly between different lgG subclass deficiency subgroups ${ }^{\mathrm{a}}$

\begin{tabular}{|c|c|c|c|c|c|}
\hline \multirow{2}{*}{$\begin{array}{l}\text { S. } \\
\text { pneumoniae } \\
\text { Serotype }\end{array}$} & \multirow[t]{2}{*}{ Dichotomous variable ${ }^{b}$} & \multicolumn{3}{|c|}{ Frequency of variable } & \multirow{2}{*}{$\begin{array}{l}P \\
\text { value }\end{array}$} \\
\hline & & $\lg G 1$ & $\lg G 3$ & $\lg G 1+\lg G 3$ & \\
\hline \multicolumn{6}{|l|}{ Responders $^{\mathrm{b}}$} \\
\hline 1 & Male & 0.8 & 0 & 0.7 & 0.006 \\
\hline 3 & Male & 0.8 & 0 & 0.7 & 0.006 \\
\hline 14 & Male & 0 & 0 & 0.5 & 0.01 \\
\hline 51 & Male & 0.8 & 0 & 0.7 & 0.006 \\
\hline \multicolumn{6}{|c|}{ Non-responders } \\
\hline 4 & Atopy & 0.06 & 1.6 & 0 & 0.02 \\
\hline 14 & Atopy & 0.17 & 1.3 & 0.2 & 0.04 \\
\hline 56 & Atopy & 0.06 & 1.6 & 0 & 0.02 \\
\hline 68 & Atopy & 0.06 & 1.6 & 0 & 0.02 \\
\hline 3 & Autoimmune condition(s) & 0 & 1.6 & 0.2 & 0.02 \\
\hline 51 & Autoimmune condition(s) & 0 & 1.6 & 0.2 & 0.02 \\
\hline 19 & Male & 0.8 & 0.06 & 1 & 0.03 \\
\hline 23 & Male & 0.8 & 0.06 & 1 & 0.03 \\
\hline 3 & Other allergy & 0.4 & 1.3 & 0.4 & 0.04 \\
\hline 51 & Other allergy & 0.4 & 1.3 & 0.4 & 0.04 \\
\hline 14 & Total variables & 0.4 & 1.3 & 0.4 & 0.03 \\
\hline
\end{tabular}

${ }^{a}$ Variables were defined as: male; diabetes; autoimmune condition(s); atopy (allergic asthma, allergic rhinitis, or allergic dermatitis/eczema); and other allergy (urticaria, angioedema, or anaphylaxis). Frequency was calculated as the mean number of each variable or total variables per patient in polyvalent pneumococcal polysaccharide vaccination responders and non-responders. ${ }^{b}$ We defined responders as patients who achieved protective levels of serotype-specific lgG postpolyvalent pneumococcal polysaccharide vaccination. We defined protective serotype-specific lgG levels as $>1.3 \mu \mathrm{g} / \mathrm{mL}$

pneumoniae serotype-specific IgG decreased with age, suggesting that the PPSV23 response stability of adults with subnormal IgGSc may be less durable than that of adults not selected for having subnormal IgGSc.

Univariate analyses demonstrated that restricted response to certain S. pneumoniae polysaccharide antigens was associated with increased prevalence of atopy (serotypes 4, 14, 56, and 68), other allergies (serotypes 3 and 51), and autoimmune condition(s) (serotypes 3 and 51) and with a predominance of male gender in patients with subnormal IgG3. In a regression analysis of aggregate response to PPSV23, atopy was associated with lower odds for responses, after adjustment for other variables. Atopy, defined as allergic asthma, allergic rhinitis,

Table 5 Characteristics of 59 index patients with subnormal lgGSc and total serum $\operatorname{lgG}>700 \mathrm{mg} / \mathrm{dL}$

\begin{tabular}{|c|c|c|c|}
\hline Characteristic & Response $^{\mathrm{a}}(n=31)$ & Non-response $^{\mathrm{a}}(n=28)$ & Value of $p^{*}$ \\
\hline Male, \% (n) & $9.7(3)$ & $25.0(7)$ & 0.1113 \\
\hline Mean age, y $( \pm 1 S D)$ & $47 \pm 11$ & $41 \pm 13$ & 0.3856 \\
\hline Mean body mass index, $\mathrm{kg} / \mathrm{m}^{2}( \pm 1 \mathrm{SD})$ & $27.7 \pm 9.7$ & $28.5 \pm 6.4$ & 0.7191 \\
\hline Autoimmune condition, \% (n) & $35.5(11)$ & $35.7(10)$ & 0.9853 \\
\hline Atopy, \% (n) & $12.9(4)$ & $46.4(13)$ & 0.0045 \\
\hline Other allergy, \% (n) & $4.8(15)$ & $53.6(15)$ & 0.6908 \\
\hline Subnormal lgG1 only, \% (n) & $19.4(6)$ & $25.0(7)$ & 0.6014 \\
\hline Subnormal lgG3 only, \% (n) & $51.6(16)$ & $60.7(17)$ & 0.4820 \\
\hline Subnormal lgG1 + lgG3 only, \% (n) & $29.0(9)$ & $14.3(4)$ & 0.1724 \\
\hline Median $\lg A, \mathrm{mg} / \mathrm{dL}$ & 182 & 186 & 0.6132 \\
\hline Median lgM, mg/dL & 110 & 89 & 0.7112 \\
\hline
\end{tabular}

${ }^{\mathrm{a}}$ Response was defined as protective levels of post-vaccination S. pneumoniae serotype-specific $\operatorname{lgG}(>1.3 \mu \mathrm{g} / \mathrm{mL})$ for $\geq 70 \%$ of serotypes tested after polyvalent pneumococcal polysaccharide vaccination

${ }^{*}$ Comparisons were made with Student's unpaired t-test, Mann-Whitney U test, Pearson's $X^{2}$ test or Fisher's exact test, as appropriate. These are nominal values of $p$. Bonferroni correction for 11 comparisons yielded a revised $p$ for significance of $<0.0045$ 
or allergic dermatitis/eczema, occurred in $29 \%$ of the present patients and in $36 \%$ of present patients with subnormal IgG3. Atopy and asthma were common in two case series of patients with subnormal IgG1 $[7,8]$ and in 121 adult patients with subnormal IgG3 [19]. Allergic asthma increases risk of lower respiratory tract infections in subjects not selected for subnormal immunoglobulin level $[43,44]$. In another study, viral or bacterial infections were detected in $70 \%$ of inpatients with exacerbation of asthma [45]. Likewise, allergic rhinitis increases risk of sinusitis [46]. These observations suggest that the combination of restricted response to certain $S$. pneumoniae polysaccharide antigens and atopy increase the risk of respiratory tract infection in persons with subnormal IgGSc.

In the present adults, PPSV23 response rates decreased with increasing age. IgG responses of elderly adults to PPSV14 or PPSV23 measured by avidity were similar to those of younger adults $[47,48]$. In contrast, concentration ratios of IgG1/IgG2 produced in response to an investigational 5-valent pneumococcal vaccine declined in adults with greater age for all serotypes studied $(6 \mathrm{~B}, 14,18 \mathrm{C}$, 19F, and 23F) [49]. In another study of elderly adults, post-vaccination IgG antibody concentrations for two serotypes $(6 \mathrm{~B}$ and $19 \mathrm{~F})$ of the five studied $(4,6 \mathrm{~B}, 14,19 \mathrm{~F}$, and $23 \mathrm{~F}$ ) were significantly lower and in vitro opsonophagocytosis of all five IgG serotype-specific antibodies was significantly reduced [50]. In two other reports, serotypespecific pre- and post-immune antibody responses measured by opsonophagocytosis were also significantly lower in elderly adults [51, 52]. IgG responses to PPS4 and PPS14 in elderly adults were associated with decreased $V_{H}$ repertoire (mostly $\mathrm{V}_{\mathrm{H}} 3$ ) and somatic mutations and with greater loss of oligoclonality than younger adults [51]. Antigen responses may differentially involve more $\mathrm{V}_{\mathrm{H}} 4$ alleles in elderly than younger adults [53].

Aggregate IgG response was lower in the present men than women with IgGSc deficiency, after adjustment for other variables. Women have higher basal levels of plasma or serum IgG $[54,55]$. Mean serum IgG levels in 26 men with Klinefelter's syndrome were significantly higher than those of control men, but after androgen replacement therapy declined to mean levels similar to those of controls [56]. IgG responses to major pneumococcal serotypes in both pre- and post-PPSV23 sera were higher in elderly men than elderly women $[48,57,58]$ but decreased significantly in women with increasing age [57]. Neither age, sex, IgG level, or IgG subclass levels were significant independent predictors of 4-fold or greater antibody response to PPSV23 [59].

The present results demonstrate that IgGSc responses to PPVS23 in adults with IgGSc deficiency are preferential and significantly associated with pre-vaccination IgGSc immunophenotypes. In IgG concentrates used to treat patients with primary antibody deficiency, IgG2 was the most active subclass of anti-Streptococcus pneumoniae antibodies by avidity and opsonophagocytosis measures, except that IgG3 was the most active against serotype $6 \mathrm{~B}$ [33]. Relatively low responsiveness to PPSV23 of the present patients with subnormal IgG3 may be due in part to their inheritance of $\mathrm{Gm} 3$ polymorphisms (allotypes) $[60,61]$. Two of the present patients had IgA deficiency. In another study, adults with IgG2/IgA deficiency had no IgG response to PPSV14 In normal adults, the predominant PPSV14 response occurred in IgG2 subclass [10], although PPSV14 responses also occur in other IgG subclasses [62]. In a subject with pneumococcal polysaccharide vaccination-specific IgG2 deficiency, the balance of specific IgG subclass antibodies changed from IgG2 > IgG1 $>$ IgG3 > IgG4 pre-vaccination to IgG1 $>$ IgG3 > IgG2 > IgG4 post-vaccination [6]. In patients with IgG2 deficiency, enhancement of IgG1 and IgG3 antibody responses to pneumococcal polysaccharide antigens suggest a change in normal switching or alteration in the antigen affinity of IgG subclass-specific antibody [36].

A strength of the present study is our evaluation of a sufficient number of adults with common subnormal IgGSc immunophenotypes to detect significant differences in some antigen-specific and aggregate IgG responses to PPSV23 and statistical associations of responses and nonresponses to other variables. Limitations of the present study include exclusion of patients with subnormal IgG2 and lack of long-term follow-up of PPSV23 response stability. Investigating mechanisms by which variables such as male sex, atopy, and autoimmunity influence PPSV23 responses in patients with subnormal IgGSc was beyond the scope of the present study.

\section{Abbreviations}

ANOVA: Analysis of variance; BMI: Body mass index; Cl: Confidence interval; Ig: Immunoglobulin; IgGSc: IgG subclass; OR: Odds ratio; PPS: Pneumococcal polysaccharide serotypes; PPSV23: Polyvalent pneumococcal polysaccharide vaccination with Pneumovax ${ }^{23}$; SD: Standard deviation

\section{Acknowledgements \\ This work was supported in part by The Binding Site Group Limited and Southern Iron Disorders Center.}

\section{Authors' contributions}

All authors contributed equally to this work. ARP, MS and SH conceived this project, performed statistical analyses, and drafted the manuscript. JCIB compiled data and performed statistical analyses. LFB evaluated and treated patients. JaCB evaluated and treated patients, performed statistical analyses, and drafted the manuscript. All authors agreed with the final version of the manuscript.

\section{Funding}

This work was supported in part by The Binding Site Group Limited and Southern Iron Disorders Center.

\section{Availability of data and materials}

All summary and many individual data generated or analysed during this study are included in this published article. Patient-by-patient datasets compiled and/or analysed during the current study are not publicly available because they could reveal personal identities. 


\section{Ethics approval and consent to participate}

This work was performed according to the principles of the Declaration of Helsinki*. Western Institutional Review Board provided an exemption under 45 CFR 46.101 (b)(4) pertinent to this study on 18 October 2018 (submission 2535878-44170911; 2 October 2018). Obtaining informed consent was not required because this study involved retrospective chart review and analyses of observations recorded in routine medical care and does not include personal identifier information.

*World Medical Association Declaration of Helsinki: ethical principles for medical research involving human subjects. JAMA 2013;310:2191-2194.

\section{Consent for publication}

Not applicable.

\section{Competing interests}

ARP, MS, and SH are employees of The Binding Site Group Limited who manufacture reagents for IgG subclass assays. JCIB, LFB, and JaCB have no duality of interests to report.

\section{Author details}

${ }^{1}$ The Binding Site Group Limited, 8 Calthorpe Road, Birmingham B15 1QT, UK. ${ }^{2}$ Southern Iron Disorders Center, Birmingham, AL, USA. ${ }^{3}$ Department of Medicine, Brookwood Medical Center, Birmingham, AL, USA. ${ }^{4}$ Department of Medicine, University of Alabama at Birmingham, Birmingham, AL, USA.

Received: 19 July 2018 Accepted: 31 July 2019

\section{Published online: 20 August 2019}

\section{References}

1. Bonilla FA, Bernstein IL, Khan DA, Ballas ZK, Chinen J, Frank MM, Kobrynski $\sqcup$, Levinson Al, Mazer B, Nelson RP Jr, et al. Practice parameter for the diagnosis and management of primary immunodeficiency. Ann Allergy Asthma Immunol. 2005:94(5 Suppl 1):S1-63.

2. Bonilla FA, Khan DA, Ballas ZK, Chinen J, Frank MM, Hsu JT, Keller M, Kobrynski LJ, Komarow HD, Mazer B, et al. Practice parameter for the diagnosis and management of primary immunodeficiency. J Allergy Clin Immunol. 2015;136(5):1186-205.

3. Picard C, Bobby Gaspar H, Al-Herz W, Bousfiha A, Casanova JL, Chatila T, Crow YJ, Cunningham-Rundles C, Etzioni A, Franco JL, et al. International Union of Immunological Societies: 2017 primary immunodeficiency diseases committee report on inborn errors of immunity. J Clin Immunol. 2018;38(1):96-128.

4. Ferrante $A$, Beard LJ, Feldman RG. IgG subclass distribution of antibodies to bacterial and viral antigens. Pediatr Infect Dis J. 1990;9(8 Suppl):S16-24.

5. Herrod HG. Clinical significance of IgG subclasses. Curr Opin Pediatr. 1993;5(6):696-9.

6. Parker A, Irure Ventura J, Sims D, Echeverria de Carlos A, Gomez de la Torre R, Tricas Aizpun L, et al. Measurement of the lgG2 response to pneumococcal capsular polysaccharides may identify an antibody deficiency in individuals referred for immunological investigation. J Immunoassay Immunochem. 2017; 38:514-22.

7. Lacombe C, Aucouturier P, Preud'homme JL. Selective IgG1 deficiency. Clin Immunol Immunopathol. 1997;84(2):194-201.

8. Barton JC, Bertoli LF, Barton JC, Acton RT. Selective subnormal lgG1 in 54 adult index patients with frequent or severe bacterial respiratory tract infections. J Immunol Res. 2016;2016:1405950.

9. Siber GR, Schur PH, Aisenberg AC, Weitzman SA, Schiffman G. Correlation between serum IgG-2 concentrations and the antibody response to bacterial polysaccharide antigens. N Engl J Med. 1980;303(4):178-82.

10. Barrett DJ, Ayoub EM. IgG2 subclass restriction of antibody to pneumococcal polysaccharides. Clin Exp Immunol. 1986;63(1):127-34.

11. Hammarström $L$, Smith $\mathrm{Cl}$. IgG2 deficiency in a healthy blood donor. Concomitant lack of $\lg G 2$, IgA and lgE immunoglobulins and specific anticarbohydrate antibodies. Clin Exp Immunol. 1983;51(3):600-4.

12. Kuijpers TW, Weening RS, Out TA. IgG subclass deficiencies and recurrent pyogenic infections, unresponsiveness against bacterial polysaccharide antigens. Allergol Immunopathol (Madr). 1992;20(1):28-34.

13. Oxelius VA, Hanson LA, Björkander J, Hammarström L, Sjöholm A. IgG3 deficiency: common in obstructive lung disease. Hereditary in families with immunodeficiency and autoimmune disease. Monogr Allergy. 1986;20:106-15.
14. Barton JC, Bertoli LF, Acton RT. HLA-A and -B alleles and haplotypes in 240 index patients with common variable immunodeficiency and selective lgG subclass deficiency in Central Alabama. BMC Med Genet. 2003;4:3.

15. Aalberse RC, Stapel SO, Schuurman J, Rispens T. Immunoglobulin G4: an odd antibody. Clin Exp Allergy. 2009;39(4):469-77.

16. Adjobimey T, Hoerauf A. Induction of immunoglobulin G4 in human filariasis: an indicator of immunoregulation. Ann Trop Med Parasitol. 2010;104(6):455-64

17. Sorensen RU, Hidalgo H, Moore C, Leiva LE. Post-immunization pneumococcal antibody titers and lgG subclasses. Pediatr Pulmonol. 1996;22(3):167-73.

18. Abrahamian F, Agrawal S, Gupta S. Immunological and clinical profile of adult patients with selective immunoglobulin subclass deficiency: response to intravenous immunoglobulin therapy. Clin Exp Immunol. 2010;159(3):344-50.

19. Barton JC, Bertoli LF, Barton JC, Acton RT. Selective subnormal lgG3 in 121 adult index patients with frequent or severe bacterial respiratory tract infections. Cell Immunol. 2016;299:50-7.

20. May A, Zielen S, von Ilberg C, Weber A. Immunoglobulin deficiency and determination of pneumococcal antibody titers in patients with therapyrefractory recurrent rhinosinusitis. Eur Arch Otorhinolaryngol. 1999;256(9):445-9.

21. Van Kessel DA, Hoffman TW, Van Velzen-Blad H, Zanen P, Rijkers GT, Grutters $J$ C. Response to pneumococcal vaccination in mannose-binding lectindeficient adults with recurrent respiratory tract infections. Clin Exp Immunol. 2014;177(1):272-9

22. Bousfiha A, Jeddane L, Picard C, Ailal F, Bobby Gaspar H, Al-Herz W, Chatila T, Crow YJ, Cunningham-Rundles C, Etzioni A, et al. The 2017 IUIS phenotypic classification for primary Immunodeficiencies. J Clin Immunol. 2018:38(1):129-43.

23. Barton JC, Bertoli LF, Barton JC. Comparisons of CVID and IgGSD: referring physicians, autoimmune conditions, pneumovax reactivity, immunoglobulin levels, blood lymphocyte subsets, and HLA-A and -B typing in 432 adult index patients. J Immunol Res. 2014;2014:542706.

24. American Diabetes Association. Diagnosis and classification of diabetes mellitus. Diabetes Care. 2013;36(Suppl 1):S67-74.

25. Tomczyk S, Bennett NM, Stoecker C, Gierke R, Moore MR, Whitney CG, Hadler S, Pilishvili T, Centers for Disease C, Prevention. Use of 13-valent pneumococcal conjugate vaccine and 23-valent pneumococcal polysaccharide vaccine among adults aged $>/=65$ years: recommendations of the advisory committee on immunization practices (ACIP). MMWR Morb Mortal Wkly Rep. 2014;63(37):822-5.

26. Pneumococcal vaccine recommendations. https://www.cdc.gov/vaccines/ vpd/pneumo/hcp/recommendations.html. Accessed 15 Aug 2019.

27. Kim JH, Park HJ, Choi GS, Kim JE, Ye YM, Nahm DH, Park HS. Immunoglobulin $\mathrm{G}$ subclass deficiency is the major phenotype of primary immunodeficiency in a Korean adult cohort. J Korean Med Sci. 2010;25(6):824-8.

28. Weinberger DM, Harboe ZB, Sanders EA, Ndiritu M, Klugman KP, Ruckinger S, Dagan R, Adegbola R, Cutts F, Johnson HL, et al. Association of serotype with risk of death due to pneumococcal pneumonia: a meta-analysis. Clin Infect Dis. 2010;51(6):692-9.

29. Song JY, Nahm MH, Moseley MA. Clinical implications of pneumococcal serotypes: invasive disease potential, clinical presentations, and antibiotic resistance. J Korean Med Sci. 2013;28(1):4-15.

30. Grabenstein JD, Musey LK. Differences in serious clinical outcomes of infection caused by specific pneumococcal serotypes among adults. Vaccine. 2014;32(21):2399-405.

31. Jefferis $R$, Kumararatne DS. Selective lgG subclass deficiency: quantification and clinical relevance. Clin Exp Immunol. 1990;81(3):357-67.

32. Kim DG, Kim C, Park S, Jung KS. Incidence of Immunoglobulin G Subclass deficiencies in patients with bronchiectasis and the clinical characteristics of patients with immunoglobulin G subclass deficiency and bronchiectasis; 2009.

33. Mikolajczyk MG, Concepcion NF, Wang T, Frazier D, Golding B, Frasch CE, Scott DE. Characterization of antibodies to capsular polysaccharide antigens of Haemophilus influenzae type $b$ and Streptococcus pneumoniae in human immune globulin intravenous preparations. Clin Diagn Lab Immunol. 2004;11(6):1158-64

34. Lindberg AA. Polyosides (encapsulated bacteria). C R Acad Sci III. 1999;322(11):925-32.

35. Hammarström L, Carbonara AO, DeMarchi M, Lefranc G, Moller G, Smith Cl, Zegers BJ. Subclass restriction pattern of antigen-specific antibodies in donors with defective expression of IgG or IgA subclass heavy chain constant region genes. Clin Immunol Immunopathol. 1987;45(3):461-70. 
36. Roberton DM, Björkander J, Henrichsen J, Söderström T, Hanson LA. Enhanced lgG1 and lgG3 responses to pneumococcal polysaccharides in isolated IgA deficiency. Clin Exp Immunol. 1989;75(2):201-5.

37. Söderström T, Söderström R, Avanzini A, Brandtzaeg P, Karlsson G, Hanson LA. Immunoglobulin G subclass deficiencies. Int Arch Allergy Appl Immunol. 1987:82(3-4):476-80.

38. Sarmiento E, Mora R, Rodriguez-Mahou M, Rodriguez-Molina J, FernandezCruz E, Carbone J. Autoimmune disease in primary antibody deficiencies. Allergol Immunopathol (Madr). 2005;33(2):69-73.

39. Barlan IB, Geha RS, Schneider LC. Therapy for patients with recurrent infections and low serum IgG3 levels. J Allergy Clin Immunol. 1993;92(2):353-5.

40. Falagas ME, Mourtzoukou EG, Vardakas KZ. Sex differences in the incidence and severity of respiratory tract infections. Respir Med. 2007;101(9):1845-63.

41. Park S, Nahm MH. Older adults have a low capacity to opsonize pneumococci due to low lgM antibody response to pneumococcal vaccinations. Infect Immun. 2011;79:314-20.

42. Parker AR, Park MA, Harding S, Abraham RS. The total IgM, IgA and IgG antibody responses to pneumococcal polysaccharide vaccination (Pneumovax ${ }^{\oplus 23}$ ) in a healthy adult population and patients diagnosed with primary immunodeficiencies. Vaccine. 2019;37(10):1350-5.

43. Martin RJ, Kraft M, Chu HW, Berns EA, Cassell GH. A link between chronic asthma and chronic infection. J Allergy Clin Immunol. 2001;107(4):595-601.

44. Mao W, Cui EH. Distribution of pathogens causing nosocomial infection in patients with bronchial asthma. Genet Mol Res. 2015;14(4):16146-50.

45. likura M, Hojo M, Koketsu R, Watanabe S, Sato A, Chino H, Ro S, Masaki H, Hirashima J, Ishii S, et al. The importance of bacterial and viral infections associated with adult asthma exacerbations in clinical practice. PLoS One. 2015;10(4):e0123584

46. Alho OP, Karttunen R, Karttunen TJ. Nasal mucosa in natural colds: effects of allergic rhinitis and susceptibility to recurrent sinusitis. Clin Exp Immunol. 2004;137(2):366-72.

47. Ruben FL, Uhrin M. Specific immunoglobulin-class antibody responses in the elderly before and after 14-valent pneumococcal vaccine. J Infect Dis. 1985;151(5):845-9.

48. Roghmann KJ, Tabloski PA, Bentley DW, Schiffman G. Immune response of elderly adults to pneumococcus: variation by age, sex, and functional impairment. J Gerontol. 1987:42(3):265-70.

49. Lottenbach KR, Mink CM, Barenkamp SJ, Anderson EL, Homan SM, Powers DC. Age-associated differences in immunoglobulin G1 (lgG1) and IgG2 subclass antibodies to pneumococcal polysaccharides following vaccination. Infect Immun. 1999;67(9):4935-8.

50. Romero-Steiner S, Musher DM, Cetron MS, Pais LB, Groover JE, Fiore AE, Plikaytis BD, Carlone GM. Reduction in functional antibody activity against Streptococcus pneumoniae in vaccinated elderly individuals highly correlates with decreased IgG antibody avidity. Clin Infect Dis. 1999;29(2):281-8.

51. Kolibab K, Smithson SL, Rabquer B, Khuder S, Westerink MA. Immune response to pneumococcal polysaccharides 4 and 14 in elderly and young adults: analysis of the variable heavy chain repertoire. Infect Immun. 2005;73(11):7465-76.

52. Kim HW, Lee S, Kim KH. Serotype 6B from a pneumococcal polysaccharide vaccine induces cross-functional antibody responses in adults to serotypes 6A, 6C, and 6D. Medicine (Baltimore). 2016;95(37):e4854.

53. Wang $X$, Stollar BD. Immunoglobulin VH gene expression in human aging. Clin Immunol. 1999:93(2):132-42.

54. Butterworth M, McClellan B, Allansmith M. Influence of sex in immunoglobulin levels. Nature. 1967;214(5094):1224-5.

55. Rhodes K, Scott A, Markham RL, Monk-Jones ME. Immunological sex differences. A study of patients with rheumatoid arthritis, their relatives, and controls. Ann Rheum Dis. 1969;28(2):104-20.

56. Kocar IH, Yesilova Z, Ozata M, Turan M, Sengul A, Ozdemir I. The effect of testosterone replacement treatment on immunological features of patients with Klinefelter's syndrome. Clin Exp Immunol. 2000;121(3):448-52.

57. Sankilampi U, Honkanen PO, Bloigu A, Herva E, Leinonen M. Antibody response to pneumococcal capsular polysaccharide vaccine in the elderly. J Infect Dis. 1996;173(2):387-93.

58. Brandao AP, de Oliveira TC, de Cunto Brandileone MC, Goncalves JE, Yara TI, Simonsen V. Persistence of antibody response to pneumococcal capsular polysaccharides in vaccinated long term-care residents in Brazil. Vaccine. 2004;23(6):762-8.

59. Hare ND, Smith BJ, Ballas ZK. Antibody response to pneumococcal vaccination as a function of preimmunization titer. J Allergy Clin Immunol. 2009;123(1):195-200.
60. Giudicelli V, Chaume D, Lefranc MP. IMGT/GENE-DB: a comprehensive database for human and mouse immunoglobulin and $T$ cell receptor genes. Nucleic Acids Res. 2005;33(Database issue):D256-61.

61. Jefferis R, Lefranc MP. Human immunoglobulin allotypes: possible implications for immunogenicity. MAbs. 2009;1(4):332-8.

62. Aaberge IS, Michaelsen TE, Heier HE. IgG subclass antibody responses to pneumococcal polysaccharide vaccine in splenectomized, otherwise normal, individuals. Scand J Immunol. 1990;31(6):711-6.

\section{Publisher's Note}

Springer Nature remains neutral with regard to jurisdictional claims in published maps and institutional affiliations.
Ready to submit your research? Choose BMC and benefit from:

- fast, convenient online submission

- thorough peer review by experienced researchers in your field

- rapid publication on acceptance

- support for research data, including large and complex data types

- gold Open Access which fosters wider collaboration and increased citations

- maximum visibility for your research: over $100 \mathrm{M}$ website views per year

At BMC, research is always in progress.

Learn more biomedcentral.com/submissions 